\title{
Integrated Computer Control System Countdown Status Messages Simulation
}

\author{
C. E. Annese
}

October 1, 1998

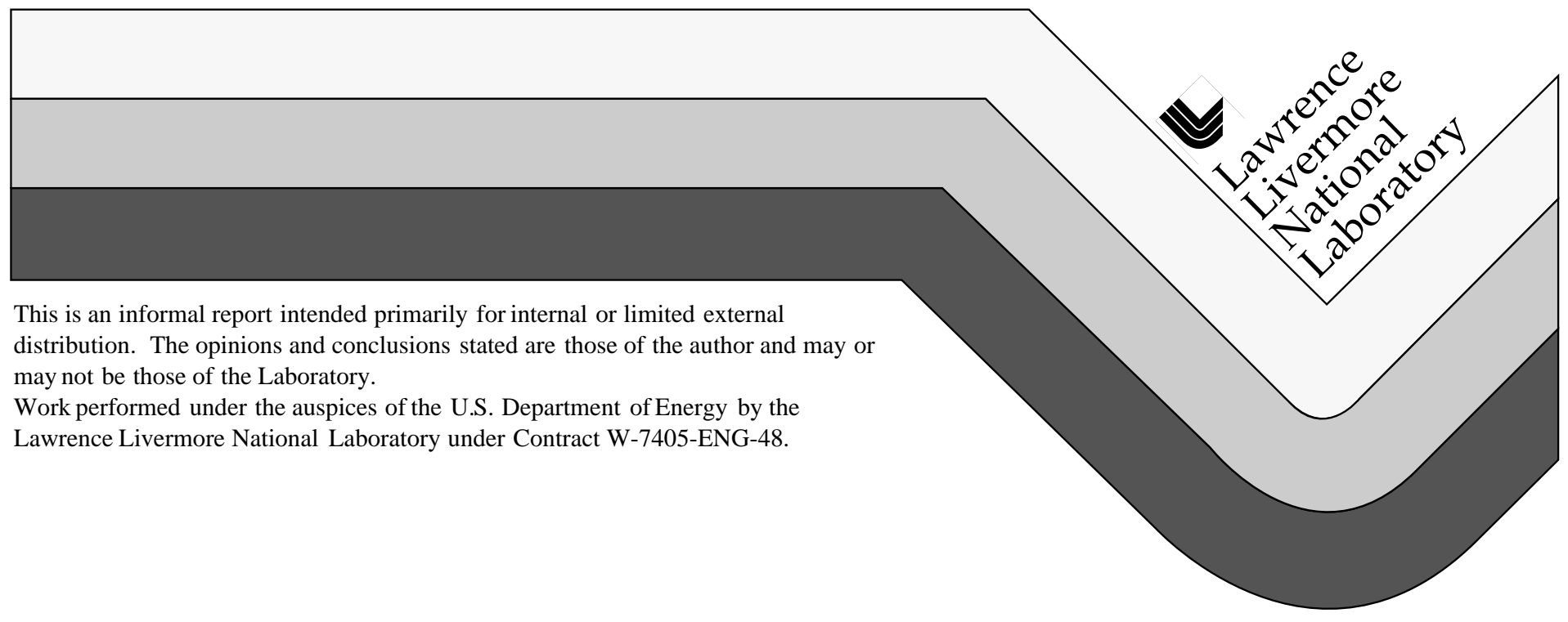




\section{DISCLAIMER}

This document was prepared as an account of work sponsored by an agency of the United States Government. Neither the United States Government nor the University of California nor any of their employees, makes any warranty, express or implied, or assumes any legal liability or responsibility for the accuracy, completeness, or usefulness of any information, apparatus, product, or process disclosed, or represents that its use would not infringe privately owned rights. Reference herein to any specific commercial product, process, or service by trade name, trademark, manufacturer, or otherwise, does not necessarily constitute or imply its endorsement, recommendation, or favoring by the United States Government or the University of California. The views and opinions of authors expressed herein do not necessarily state or reflect those of the United States Government or the University of California, and shall not be used for advertising or product endorsement purposes.

This report has been reproduced directly from the best available copy.

Available to DOE and DOE contractors from the Office of Scientific and Technical Information P.O. Box 62, Oak Ridge, TN 37831

Prices available from (423) 576-8401

Available to the public from the National Technical Information Service

U.S. Department of Commerce 5285 Port Royal Rd. Springfield, VA 22161 


\section{Integrated Computer Control System}

\section{Countdown Status Messages Simulation}

FY98 LDRD Project

C. E. Annese

October, 1998

UCRL-ID-133242 


\section{Introduction}

\subsection{Background}

The Integrated Computer Control System (ICCS) CORBA-Based Simulation LDRD wa guide the design of the complex ICCS framework in its application to the Na (NIF) and thereby reduce performance risks. A simulation study was perform Milestone to "Develop Shot Cycle Workflow Simulation." Status messages fri shot countdown activities were included in a discrete event simulation to as on commercial components and their utilization in current designs.

\subsection{Objective}

The purpose of the study was to use simulation to help validate the design messages during countdown will not overload the network; i.e., that the com: sized to handle the expected traffic.

\subsection{Scope}

The scope of the present study was to layout the framework for the Status $N$ Simulation (SMCS) using the discrete event simulation package, SIMPROCESS, $t$ inputs for running the model, and to obtain estimates of resource utilizati becomes available, inputs can be updated to include additional refinements, SIMPROCESS has a "Design of Experiments" capability which can be used to evi scaling ICCS component utilization and resource allocation on system behavi not been implemented at this time.

\section{Design Description}

\subsection{Countdown Activities}

Figure 2-1 shows the activities during a typical NIF countdown. The figure to scale, with the 'countdown' arrow representing five minutes. The four i engineers to include as part of the SMCS are 1) plasma electrode Pockels ce 2) wavefront control, 3) preamplifier module (PAM) charging, and 4) main an Status messages will arise from each of these activities as they monitor th, the status on to the supervisory console for that system. The rate and si each of the application's front-end processors (FEP) and on to the supervis obtained by interviews with experts and from NIF interface control document description and latencies were obtained from network designers and were scal represent the network interfaces for each of the four countdown activities activities and from the network latencies relevant to the simulation will b sections.

\subsubsection{PEPC Conditioning Status Messages}

There are three PEPC FEPs for each NIF cluster of 48 laser beamlines. The (PM) FEP, 2) a plasma pulser / gas and vacuum (PPGV) FEP, and 3) a switch pr povide a table describing the worst case scenario for PEPC device monitorin FEPs to the supervisory system during the five minute pre-shot countdown ( $t$ and 2-2 show the peak operation message traffic from the PM and PPGV FEPs, no message traffic from the SP FEP during countdown. The PEPC FEPs travel FEP through a $10 \mathrm{Mb} / \mathrm{s}$ fiber; and from the $10 / 100 \mathrm{Mb} / \mathrm{s}$ ethernet switch thror 
line to the core ethernet and out to the supervisory consoles. Figure 2-2 the ethernet connections from client to server FEP. Details of the PEPC $F$ the first ethernet switch are shown in Figure 2-3. The packet size and byte 2-2 will provide inputs to the simulation.

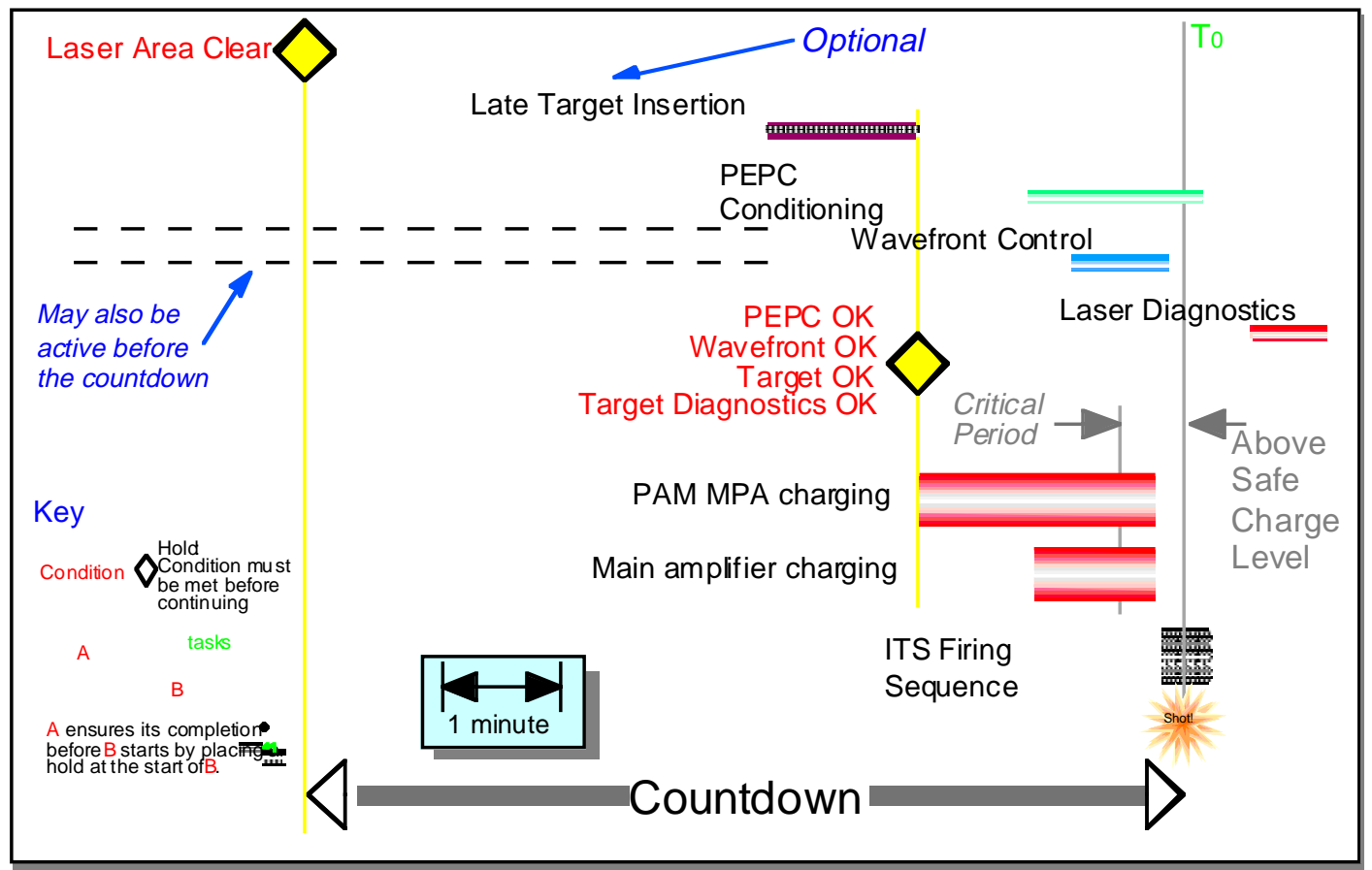

Figure 2-1. ICCS activities during countdown.

Table 2-1. Peak operation message traffic from PEPC PM FEP during countdor

\begin{tabular}{|c|c|c|c|c|c|c|c|c|c|}
\hline $\begin{array}{l}\text { PEPC } \\
\text { FEP } \\
\end{array}$ & Device & $\begin{array}{l}\text { Device } \\
\text { Count }\end{array}$ & Signals & $\begin{array}{l}\text { Signal } \\
\text { Device }\end{array}$ & $\begin{array}{l}\text { /Total } \\
\text { Signals }\end{array}$ & $\begin{array}{c}\text { Rate } \\
(\mathrm{Hz})\end{array}$ & $\begin{array}{l}\text { Msg } \\
\text { sec } \\
\end{array}$ & $\begin{array}{l}\text { / Bytes } \\
\text { Msg }\end{array}$ & $\begin{array}{l}\text { / Bytes } \\
\text { sec }\end{array}$ \\
\hline $\begin{array}{l}\mathrm{PM} \\
\text { Solaris }\end{array}$ & $\begin{array}{l}\text { plasma } \\
\text { current }\end{array}$ & 4 & $\begin{array}{l}\text { plasma } \\
\text { current }\end{array}$ & 1 & 4 & 0.2 & 1 & 16,000 & 16,000 \\
\hline $\begin{array}{l}\text { PM } \\
\text { Solaris }\end{array}$ & $\begin{array}{l}\text { switch } \\
\text { voltage }\end{array}$ & 8 & $\begin{array}{l}\text { switch } \\
\text { voltage }\end{array}$ & 1 & 8 & 0.2 & 1 & 32,000 & 32,000 \\
\hline Total & & & & & & & 2 & & 48,000 \\
\hline
\end{tabular}


Table 2-2. Peak operation message traffic from PEPC PPGV FEP during countc

\begin{tabular}{|c|c|c|c|c|c|c|c|c|c|}
\hline $\begin{array}{l}\text { PEPC } \\
\text { FEP }\end{array}$ & Device & $\begin{array}{l}\text { Device } \\
\text { Count }\end{array}$ & Signals & $\begin{array}{l}\text { Signal } \\
\text { Device }\end{array}$ & $\begin{array}{l}\text { /Total } \\
\text { Signals }\end{array}$ & $\begin{array}{l}\text { Rate } \\
(\mathrm{Hz})\end{array}$ & $\begin{array}{l}\text { Msg } \\
\text { sec }\end{array}$ & $\begin{array}{l}\text { / Bytes } \\
\text { Msg }\end{array}$ & $\begin{array}{l}\text { / Bytes } \\
\text { sec }\end{array}$ \\
\hline $\begin{array}{l}\text { PPGV } \\
\text { vxworks }\end{array}$ & simmer & 48 & $\begin{array}{l}\text { current \& } \\
\text { voltage }\end{array}$ & 2 & 96 & 0.2 & 1 & 48,000 & 48,000 \\
\hline $\begin{array}{l}\text { PPGV } \\
\text { Vxworks }\end{array}$ & $\begin{array}{l}\text { PEPC } \\
\text { pressure }\end{array}$ & 24 & $\begin{array}{l}\text { gas \& } \\
\text { vacuum } \\
\text { pressure }\end{array}$ & 2 & 48 & 1 & & & \\
\hline $\begin{array}{l}\text { PPGV } \\
\text { vxworks }\end{array}$ & $\begin{array}{l}\text { PEPC } \\
\text { gauges }\end{array}$ & 84 & pressure & 1 & 84 & 1 & 1 & 528 & 528 \\
\hline Total & & & & & & & 2 & & 48,528 \\
\hline
\end{tabular}

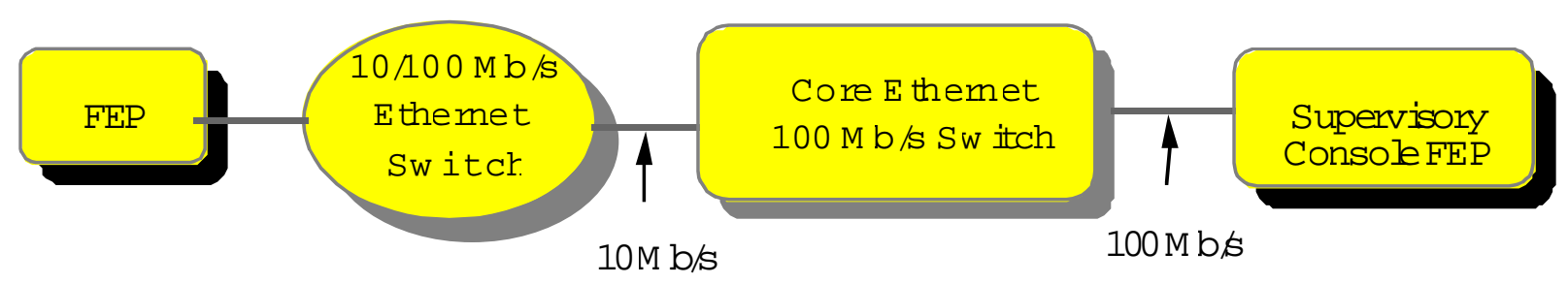

Figure 2-2. Typical client FEP to server FEP ethernet.

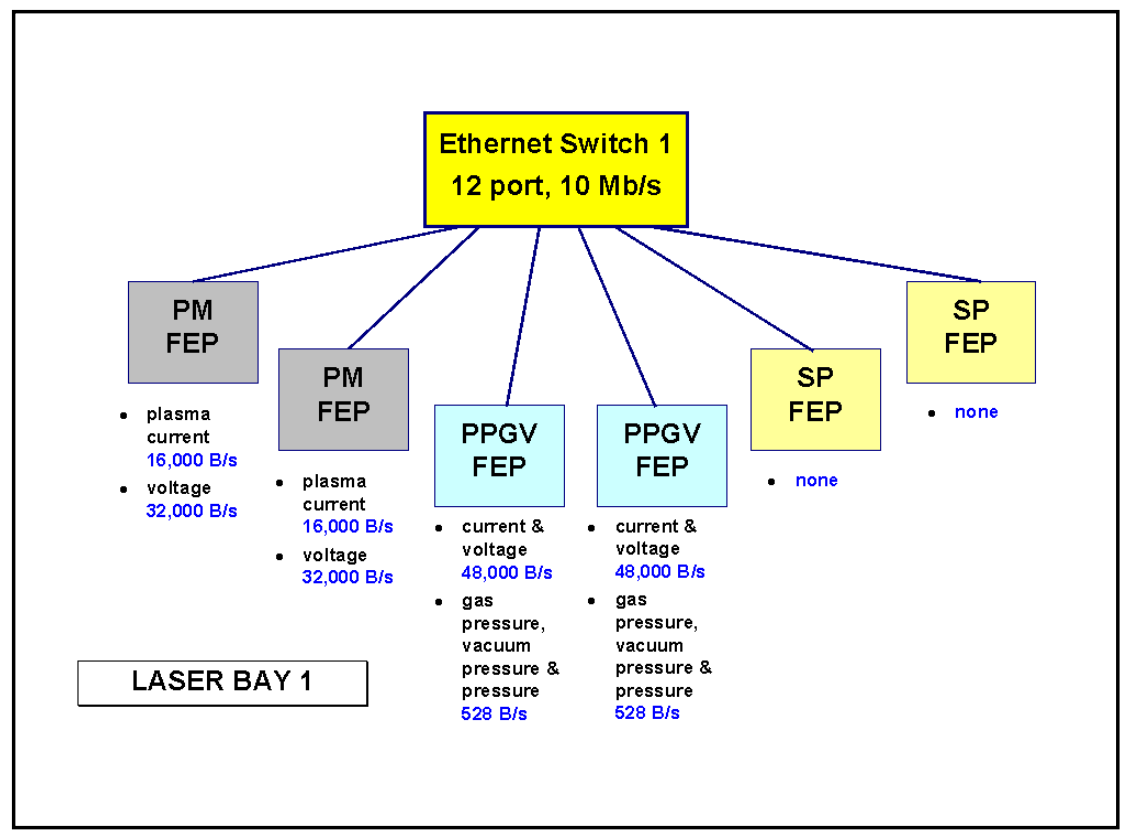

Figure 2-3. PEPC Ethernet system diagram.

\subsubsection{Wavefront Control Status Messages}

Wavefront control status messages during countdown were obtained from conve system designer. Figure 2-4 illustrates the size and types of messages usec 


\subsubsection{PAM MPA Charging Status Messages}

There are 48 PAM FEPs. Status message size and delivery rates were obtaine with design engineers. There is one voltage status message for each PAM FEI is 4 Bytes long and is generated at once per second. Though there are four countdown of Figure 2-1 that appear to coincide with the start of the PAM ( wavefront OK, target OK, and target diagnostics OK, the start of the PAM cr on receiving any of these OK signals; the charging starts two minutes prior summarizes this status message from the PAM for easy reference. As for the messages travel from the application FEP through a $10 \mathrm{Mb} / \mathrm{s}$ fiber; and from switch through a $100 \mathrm{Mb} / \mathrm{s}$ ethernet line to the core ethernet and out to th

The packet size and bytes/sec from Table 2-3 will provide inputs to the sim the PAM Ethernet layout used in the simulation.

\section{Wavefront ETHERNET SYSTEM DIAGRAM}

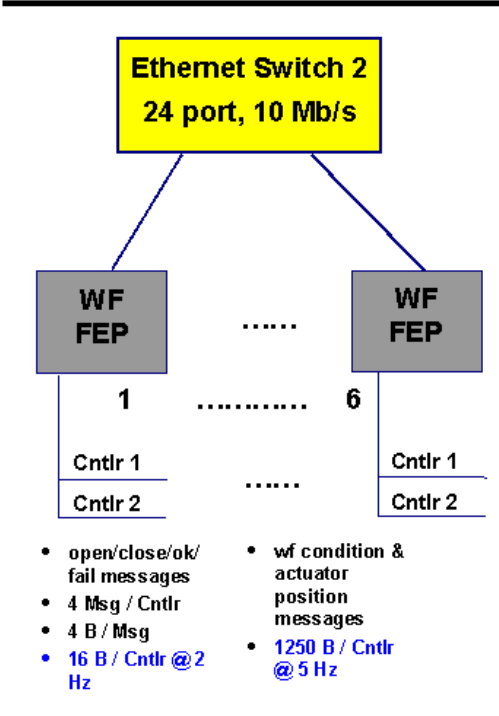

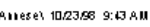

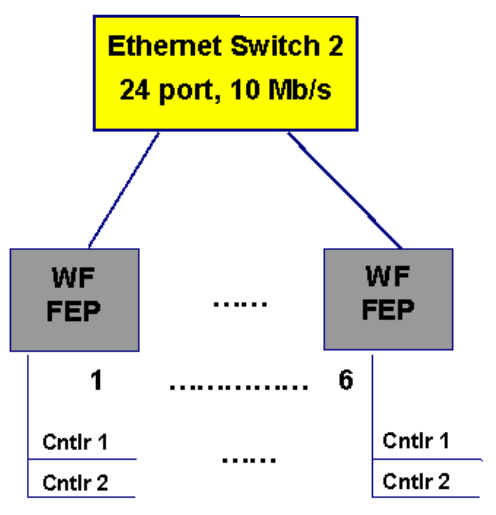

LASER BAY 1

Fgure 2 4. Wavefront message size and types used in the countdown simulatic

Table 2-3. Peak operation message traffic from PAM FEP during five minute

\begin{tabular}{|c|c|c|c|c|c|c|c|c|c|}
\hline $\begin{array}{l}\text { PAM } \\
\text { FEP } \\
\end{array}$ & Device & $\begin{array}{l}\text { Device } \\
\text { Count }\end{array}$ & Signals & $\begin{array}{l}\text { Signal } \\
\text { Device }\end{array}$ & $\begin{array}{l}\text { / Total } \\
\text { Signals } \\
\end{array}$ & $\begin{array}{c}\text { Rate } \\
(\mathrm{Hz})\end{array}$ & $\begin{array}{l}\text { Msg / } \\
\text { sec }\end{array}$ & Bytes & $\begin{array}{c}\text { / MsgBytes } \\
\text { sec }\end{array}$ \\
\hline & chargi & 48 & voltag $\epsilon$ & 1 & 48 & 1 & 1 & $4 \star 48$ & $=19292$ \\
\hline
\end{tabular}




\subsubsection{Main Amplifier Charging Status Messages}

Figure 2-6 shows the main amplifier power conditioning ethernet system diag simulation. The main capacitors will start charging at $\sim 77$ seconds prior to ionization lamp check (PILC) capacitors will start charging at 31 seconds status message during countdown, therefore, will consist of a floating poin voltage starting at 77 seconds prior to shot, at half second intervals; the concurrent with a second floating point value for PILC capacitor voltage st to shot, also at half second intervals. The timing system will wait for per PILC modules before going into the final two seconds of countdown.
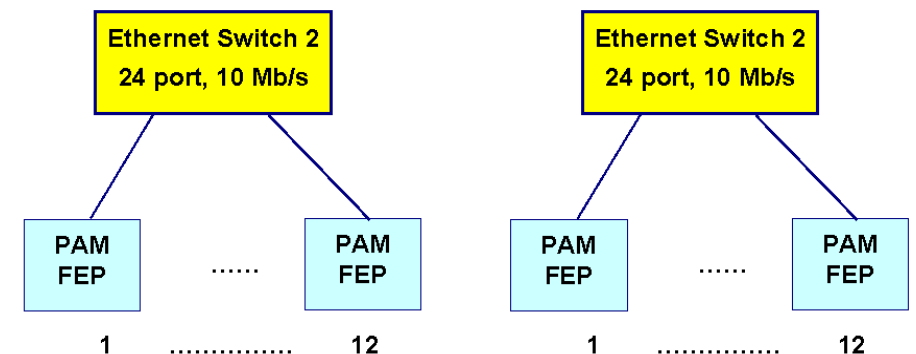

- $4 \mathrm{~B} / \mathrm{msg}$ for each of 12 FEPs @ $1 \mathrm{~Hz}$

- $4 \mathrm{~B} / \mathrm{s}$

LASER BAY 1

Figure 2-5. PAM Ethernet system diagram.

\subsection{Transaction Time Measurements}

\subsubsection{FEP and Network Description}

Experimental latency times for the FEPs were derived from measurements incl application takes to interface with CORBA, with the transmission control $p$ protocol (TCP/IP) protocol, and the network interface card driver. Figure configuration used for the measurements. Table 2-4 shows an example of the various portions of the ICCS network from application FEPs, through Ethernt ethernet switch, and on to the supervisory FEP. These times were measured connects a typical FEP client through Ethernet to a supervisory server. An bits, often expressed 6 hexadecimal 8-bit words separated by columns. The sent is 1500 bytes.

\subsubsection{Message Overheads}

Message sizes are increased by overhead added from CORBA, TCP, and IP. The describe the size and types of information added to the message packets. 
TCP Protocól

TCP provides timely and ordered data delivery, connection establishment, da termination, and full duplex. It adds around 20 bytes to the original mess packet switching mode, which means that data is separated into smaller pack, sequence numbers, does not necessarily arrive at the destination in the same at the destination in the proper order according to the sequence numbers. flow control and error checking, urgent ("out-of-band" data, data stream pr and reporting service failures). Ports 1 - 1023 are reserved for applicati 1024 to above can be used as long as no one else is using them. TCP lets $y^{\prime}$ successful. There are 16 bits for port numbers, so there are 64,000 ports $\bar{c}$ maximum packet size that can be sent prior to waiting for an acknowledgment TCP packet format is as shown in Table 2-5.

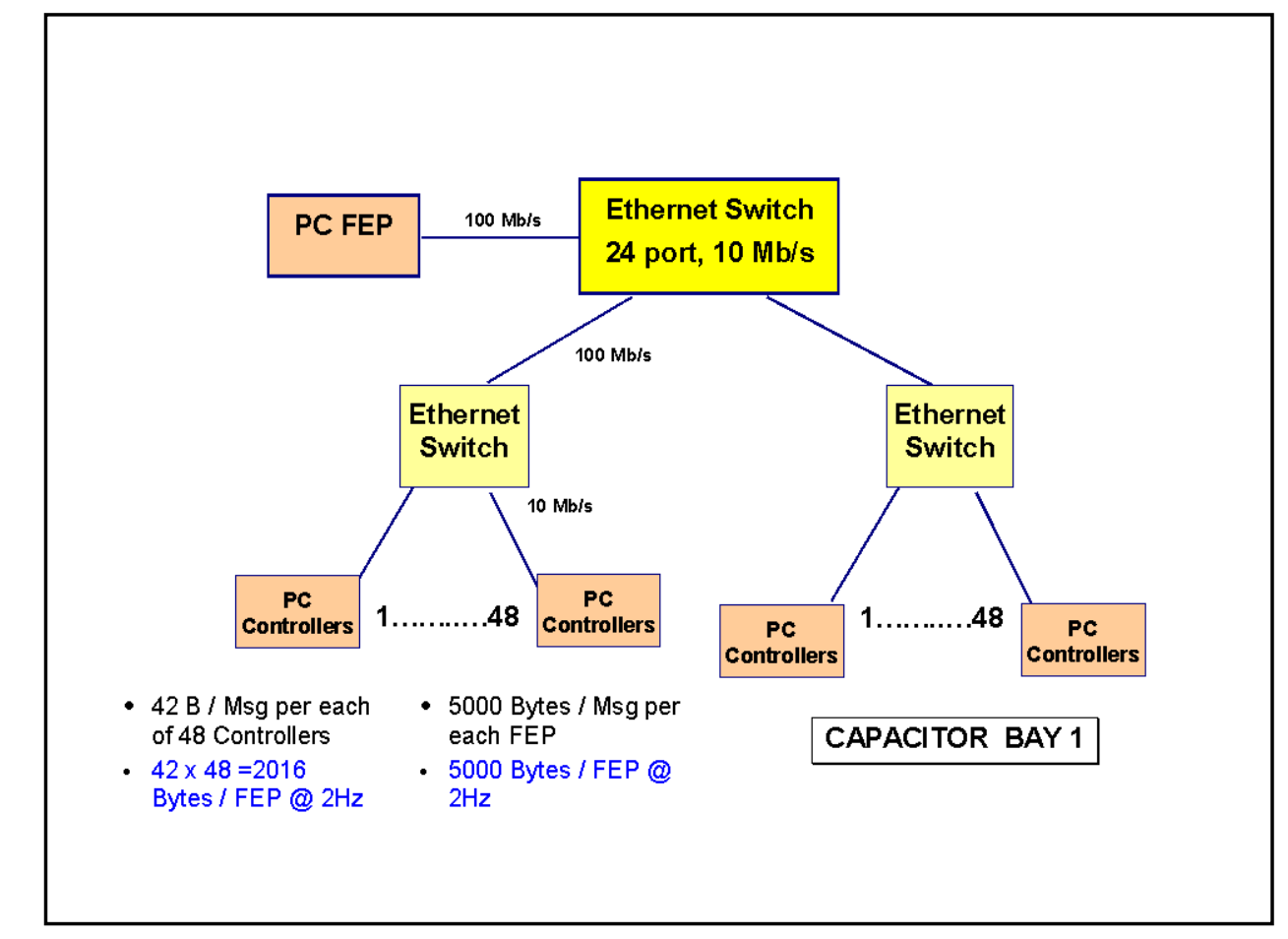

Figure 2-6. Main amplifier power conditioning Ethernet system diagram.

\footnotetext{
${ }^{1}$ Eugene Pinsky, Massachusetts Institute of Technology, TCP/IP Networking course notes from Boston University via satellite to LLNL, LTV 1366, 5/98, p. 4-6.
} 


\section{Transactions}

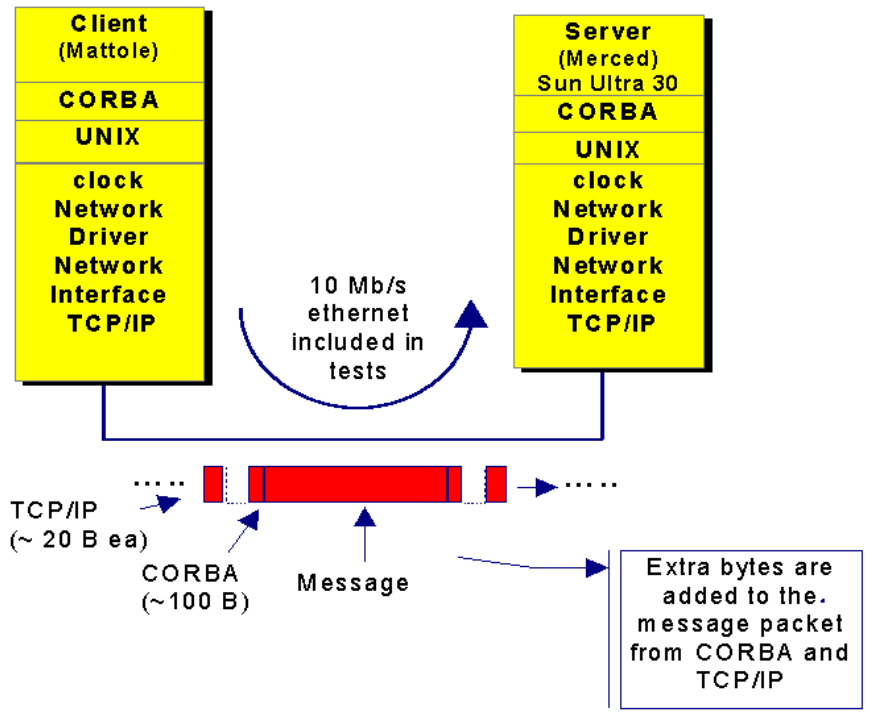

Figure 2-7. Measurements were made of transaction times between Sun Ultrasf $10 \mathrm{Mb} / \mathrm{s}$ ethernet in-between.

IP Protocol 1

Internet Protocol makes "best effort" delivery, utilizes fragmentation and mechanism for end-to-end reliability, flow control or sequencing. Thus it provide the added functions and reliability. See Table 2-6 for details. T protocol identifier, such as TCP, UDP (user datagram protocol), or ICMP, fc datagram contains 32-bit IP addresses. IP adds 20 bytes in length to each addition to the 20+ bytes added by TCP. Common object-request broker archit protocol adds about 100 bytes of data to each message.

CORBA

Corba adds about 100 bytes of data to each message.

\footnotetext{
${ }^{2}$ Conversation with Eric Stout, LLNL.
} 
Table 2-4. Transactions per second from Mattole to Merced through $10 \mathrm{Mb} / \mathrm{s}$

\begin{tabular}{|c|c|c|c|c|c|c|c|c|}
\hline $\begin{array}{l}\text { Message } \\
\text { Size } \\
\text { (FPA) }\end{array}$ & $\begin{array}{l}\text { Byte Siz } \\
\mathrm{FPA} * 4\end{array}$ & $\begin{array}{ll} & \text { Client } \\
\text { Time } & \text { (msec } \\
\text { Utiliz }\end{array}$ & $\begin{array}{l}\text { Pocess } \\
/ \mathrm{CPU} \\
\text { ion } \\
\end{array}$ & $\begin{array}{l}\text { Server } \\
\text { Time } \\
\text { (msec ) }\end{array}$ & ocess & $\begin{array}{l}\text { Client Nu } \\
\text { CPU } \\
\text { Utilizati }\end{array}$ & $\begin{array}{l}\text { Server } \\
\text { Null CPU } \\
\text { nUtilizat }\end{array}$ & $\begin{array}{l}\text { Clock } \\
\text { Time }\end{array}$ \\
\hline 2 & 8 & .545 & .44 & .452 & .37 & .48 & .25 & 1.233 \\
\hline 4 & 16 & .545 & .44 & .473 & .38 & .47 & .26 & 1.229 \\
\hline 8 & 32 & .545 & .43 & .462 & .37 & .47 & .28 & 1.254 \\
\hline 16 & 64 & .548 & .43 & .388 & .30 & .48 & .29 & 1.284 \\
\hline 32 & 128 & .552 & .41 & .443 & .33 & .47 & .28 & 1.346 \\
\hline 64 & 256 & .548 & .38 & .281 & .19 & .47 & .31 & 1.457 \\
\hline 128 & 512 & .554 & .33 & .412 & .24 & .47 & .29 & 1.700 \\
\hline 256 & 1024 & .566 & .26 & .544 & .25 & .46 & .30 & 2.195 \\
\hline 512 & 2,048 & .634 & .20 & .643 & .20 & .47 & .28 & 3.152 \\
\hline 1,024 & 4,096 & .733 & .14 & .932 & .18 & .48 & .28 & 5.096 \\
\hline 2,048 & 8,192 & .917 & .10 & 1.301 & .15 & .47 & .31 & 8.934 \\
\hline 4,096 & 16,384 & 1.128 & .07 & 2.223 & .13 & .46 & .31 & 17.060 \\
\hline 8,192 & 32,768 & 1.600 & .05 & 3.701 & .11 & .47 & .30 & 32.758 \\
\hline 16,384 & 65,536 & 2.583 & .04 & 7.098 & .10 & .48 & .26 & 68.134 \\
\hline 32,768 & 131,072 & 4.578 & .03 & 14.912 & .11 & .46 & .31 & 132.143 \\
\hline 65,536 & 262,144 & 8.769 & .03 & 29.224 & .11 & .47 & .30 & 260.339 \\
\hline 131,072 & 524,288 & 17.384 & .03 & 63.220 & .11 & .46 & .30 & 516.352 \\
\hline
\end{tabular}

Table 2-5. TCP adds at least 20 bytes in length (assumes 8 bits/byte) to e

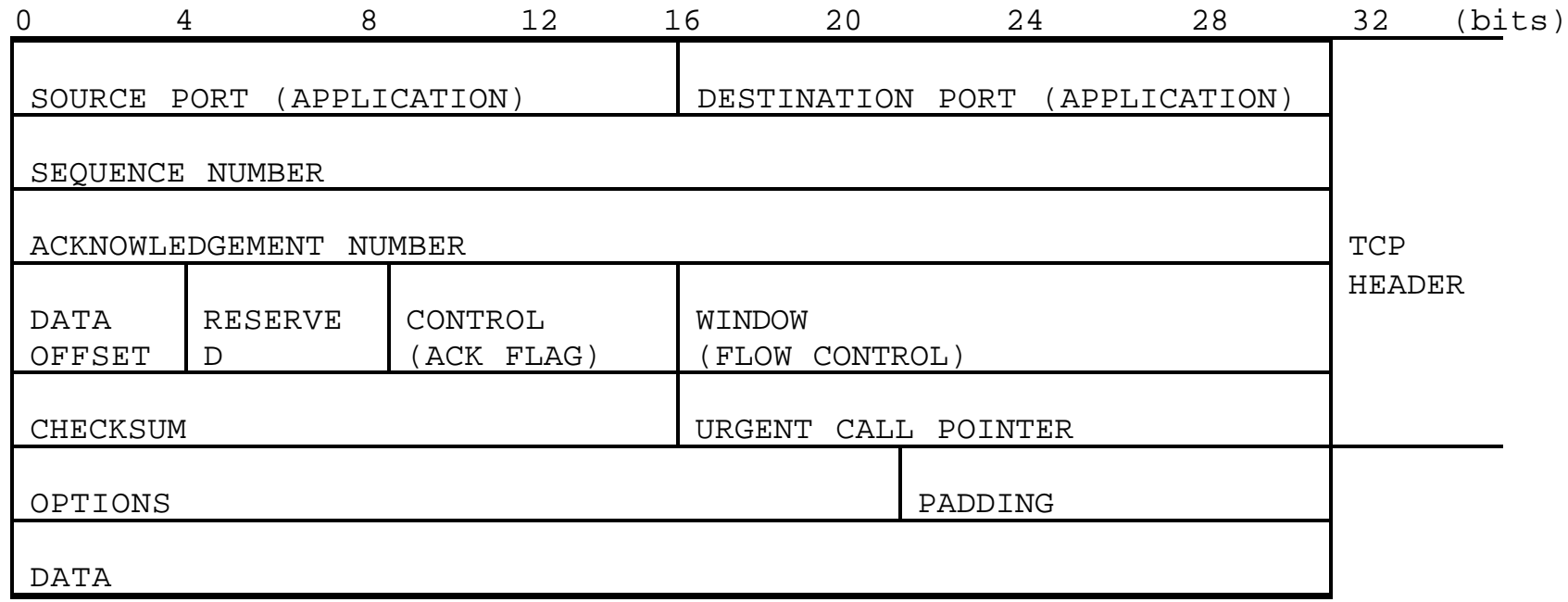

\subsubsection{Experimental Measurements of Latencies}

Assessment of the transactions times in Table 2-4 led to the creation of $f$ and supervisor FEP latencies, and $10 \mathrm{Mb} / \mathrm{s}$ Ethernet latencies. An overhead transaction is attributed that leads to the following three formulations in

Client FEP Latency

Server FEP Latency

$10 \mathrm{Mb} / \mathrm{s}$ Ethernet Latency

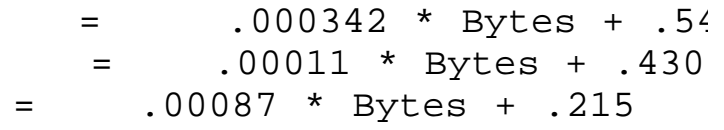

The ratio of the formulation to the actual data is shown in Figures 2-8, 2 for client FEP, server FEP, and $10 \mathrm{Mb} / \mathrm{s}$ Ethernet latencies. 
Table 2-6. IP adds at least 20 bytes in length (assumes 8 bits/byte) to ear

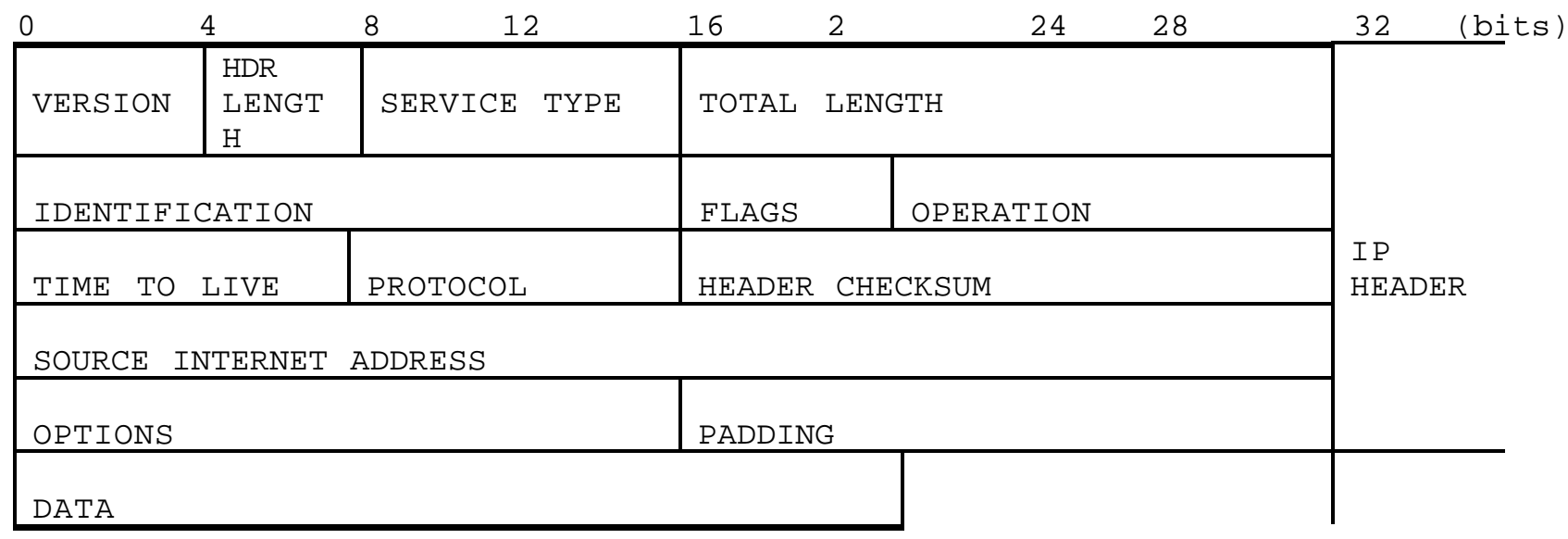

Client FEP Latency has an Overhead of .545 Milliseconds

for any Byte Size, then Latency can be Estimated to $+/-10 \%$

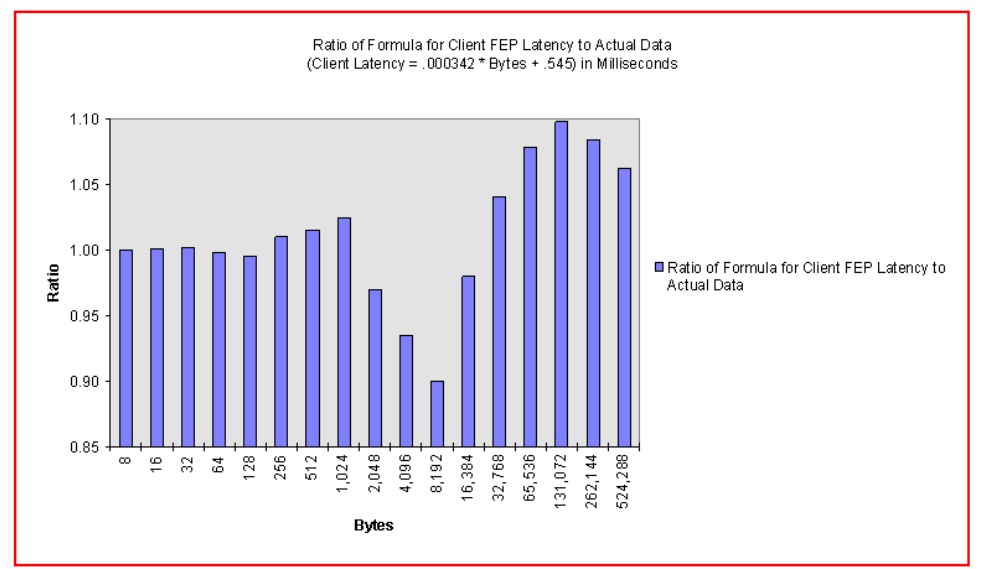

Figure 2-8. Client FEP latency can be estimated to $+/-10 \%$. 
Server FEP Latency has an Overhead of .545 Milliseconds

for any Byte Size, then Latency can be Estimated to $+/-10 \%$

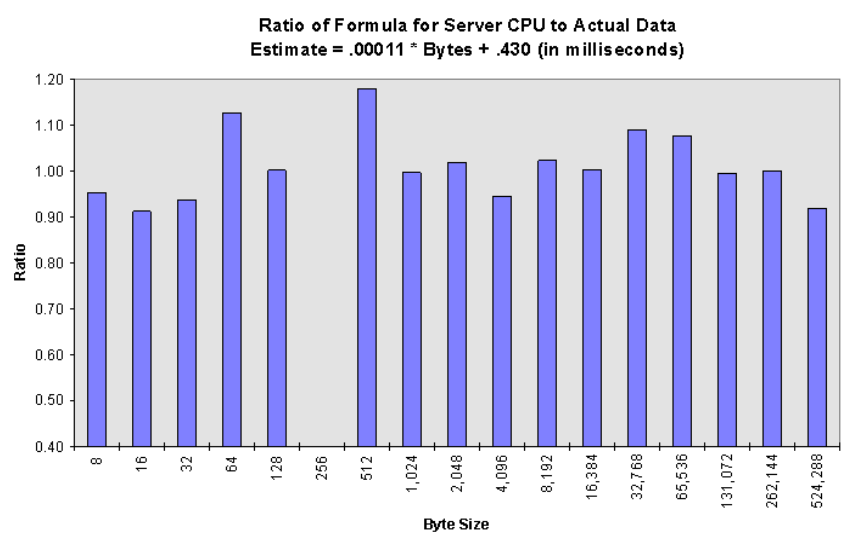

Figure 2-9. Server FEP latency can be estimated to +/- 10\%.

$10 \mathrm{Mb} / \mathrm{s}$ Ethernet Latency has an Overhead of $\sim 219$ Milliseconds for any Byte Size; then Latency can be Estimated to $+/-10 \%$ for all but two points

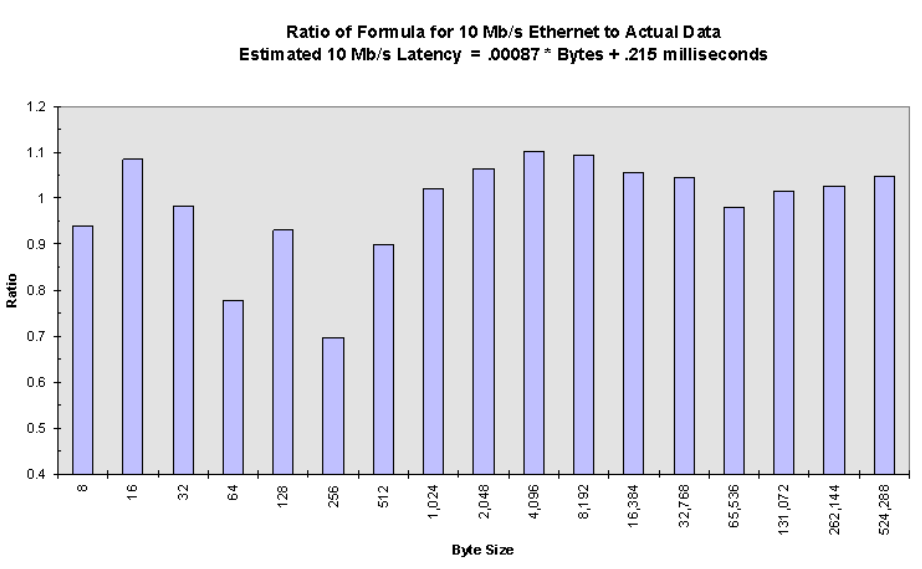


a) Wave fontupevior

b) Ma in Amp
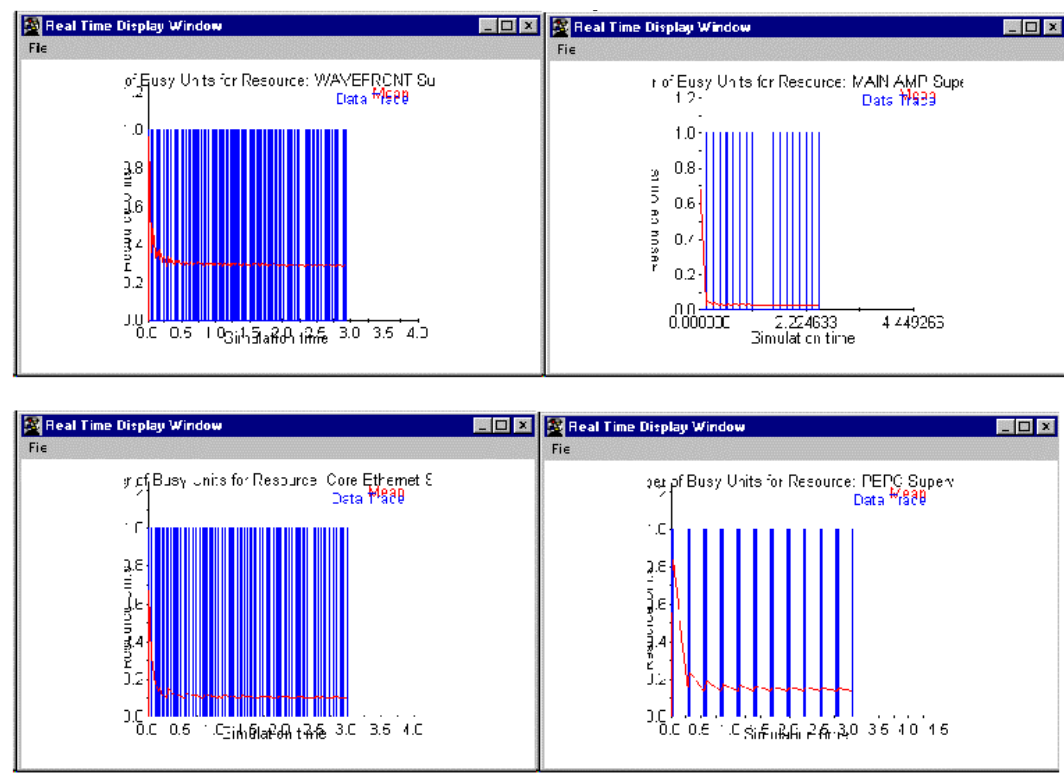

c) CorettenetSwitch

d) PEPC Supervior

Figure 2-11. Average percent resources busy during busiest time of five-mir

The resource utilization vs simulation time is plotted in Figure $2-11$ for $\epsilon$ status messages. The x-axis represents simulation time in hours; however, had shown that simprocess did not work well using fractions of seconds as in represented as 1 second, and a second was represented as 1000 seconds. So, 0.28 hours on the graph, represents one second in the model.

The time that resources spent waiting for resources was also tallied and va: milliseconds for the main amp power conditioning signals to around 80 milli: current and voltage signals.

\section{Discussion}

To conservatively assess the demand on the system, the simprocess model was represents the period when all messages occur simultaneously. Data was col average percent of resources busy. These vary from less than $0.001 \%$ for t] to over 20\% for the wavefront supervisor. They are shown in Figure 3-1.

\section{Conclusions}

The Simprocess status message simulation provides a good visual tool for unc network utilization. Supervisory displays and their latencies will vie for included in the model when they become available. While point estimates har

\footnotetext{
${ }^{3}$ Bar for wavefront Ethernet switch 1 also includes $10 \mathrm{Mb} / \mathrm{s}$ Ethernet plus the switch.

${ }^{4}$ Conversation with B. Kettering who ran Status Monitor simulation with Simprocess and discovered that Simprocess did not work well using fractions of seconds as inputs to the model.
} 
work, statistical distributions can easily be used in their place and a des: will allow variation of parameters for optimization when loads start to look heavy.

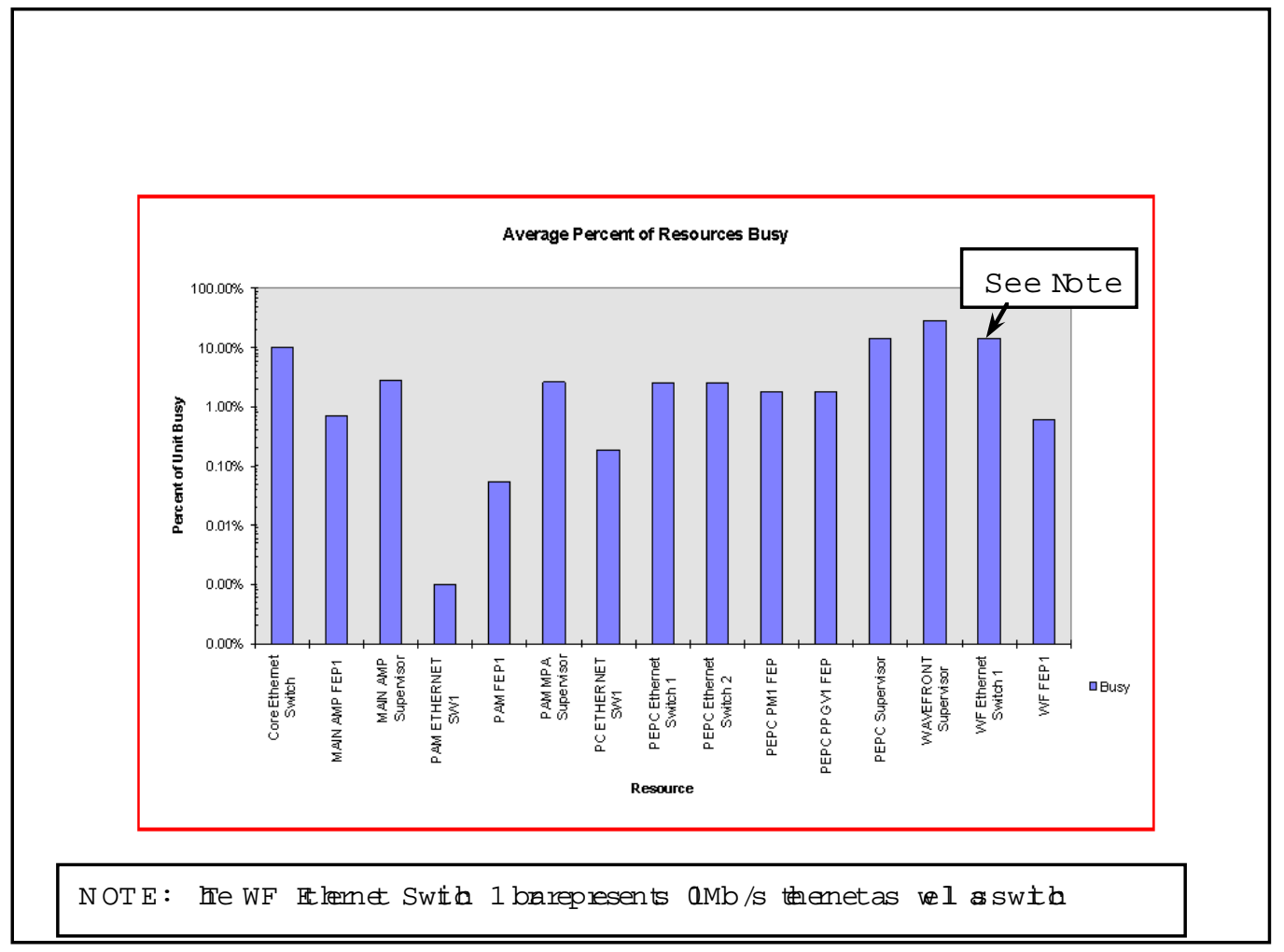

Figure 3-1. Resource utilization vs simulation time for four resources. 